\title{
CONTAGEM DE CÉLULAS SOMÁTICAS E CARACTERÍSTICAS PRODUTIVAS DE VACAS DA RAÇA HOLANDESA EM LACTAÇÃO' 1
}

\author{
Alfredo Ribeiro Pereira2*; Paulo Fernando Machado; Gabriel Adrian Sarríes ${ }^{4}$ \\ ${ }^{2}$ CEETEPS - ETE "Benedito Storani", Av. Antonio Pincinato, 4355 - CEP: 13211-771 - Jundiaí, SP. \\ ${ }^{3}$ Depto. de Produção Animal - USP/ESALQ, C.P. 9 - CEP: 13418-900 - Piracicaba, SP. \\ ${ }^{4}$ Depto. de Ciências Exatas - USP/ESALQ. \\ ${ }^{*}$ Autor correspondente <alfredopereira@hotmail.com>
}

\begin{abstract}
RESUMO: A mastite subclínica, diagnosticada através da contagem de células somáticas, afeta negativamente a pecuária leiteira diminuindo a produção de leite e de gordura. Este estudo foi realizado com o objetivo de se quantificar o efeito do nível de células somáticas, transformado para escore linear (EL), sobre a produção de leite e gordura em 305 dias de lactação, produção de leite no pico e duração da lactação de bovinos da raça holandesa. Foram levantadas informações referentes a 147 lactações encerradas de vacas da raça holandesa (83 primíparas e 64 multíparas), de um rebanho confinado do Estado de São Paulo. As análises estatísticas foram realizadas utilizando-se o procedimento de modelo lineares generalizados. Contrariando a literatura, as características produtivas dos animais primíparos não sofreram efeito do escore linear. Provavelmente este fato ocorreu devido a quase inexistência de animais primíparos com EL maior que 4,5. O aumento do escore linear médio durante a lactação levou a diminuição da produção de leite e gordura em 305 dias de lactação. O aumento do escore linear médio durante o início da lactação levou a diminuição da produção de leite no pico da lactação.

Palavras-chave: CCS, mastite, produção de leite, produção de gordura, duração da lactação
\end{abstract}

\section{SOMATIC CELL COUNT AND PRODUCTION CHARACTERISTICS OF LACTATING HOLSTEIN COWS}

\begin{abstract}
Subclinical mastitis results in the decrease of milk and fat production. This disease is detected using somatic cell counts. The objective of this study was to quantify the relation of somatic cell levels, transformed into linear score (LS), and the production of milk and fat during 305 days of lactation, peak milk production, and the lactation duration time of Holstein cattle. Data were gathered concerning 147 closed lactations of Holstein cows (83 primiparous and 64 multiparous) from a confined herd in the state of São Paulo, Brazil. Statistical analyses were performed through the general linear model procedure. The productive characteristics of multiparous, but not primiparous cows, were affected acording to the linear score. An increase in the average linear score during lactation resulted in the decrease of fat and milk production in the 305 days of lactation. The increase in the average linear score at the beginning of the lactation period resulted in a decrease of milk production at the peak of lactation.
\end{abstract}

Key words: SCC, mastitis, milk production, fat production, lactation length

\section{INTRODUÇÃO}

A mastite é um processo inflamatório da glândula mamária acompanhado da redução de secreção de leite e mudança de permeabilidade da membrana que separa o leite do sangue. Normalmente é causada pelo desenvolvimento de microrganismos, principalmente bactérias, no interior da glândula mamária (Machado et al., 1998). Esta doença é considerada a mais custosa para a atividade leiteira por alguns autores. Estima-se que as perdas econômicas mundiais causadas por ela chegam a 35 bilhões de dólares por ano e nos EUA os prejuízos anuais seriam de 2 a 4 bilhões de dólares (Polititis et al., 1995; Giraudo et al., 1997). No Brasil não existem estatísticas confiáveis, mas estima-se que as perdas sejam grandes.
Os sintomas apresentados pelo animal acometido permitem a classificação da mastite. Quando os sinais da inflamação são visíveis, como por exemplo a presença de grumos no leite ou o inchaço da glândula mamária se diz que é um caso clínico. Se existe a necessidade do uso de testes específicos de deteç̧ão, como por exemplo a contagem de células somáticas (CCS) ou o "CMT" diz se que é um caso subclínico (Jain, 1979; Philpot, 1979; Blood \& Radotitis, 1989; Philpot \& Nickerson, 1991).

A mastite subclínica ocorre em todos os rebanhos leiteiros do Brasil. Vários levantamentos realizados de 1970 até hoje apontam alta incidência desta doença, com índices variando de $11,9 \%$ a $58,8 \%$ de vacas infectadas por rebanho (Langenegger et al., 1970; Nader Filho et al., 1985; Laranja \& Machado, 
1994). Além da produção de leite, outras características produtivas como a produção de gordura e a duração da lactação também são afetadas (Machado et al., 1993; Gadini et al., 1997; Norman et al., 1999).

Os efeitos da mastite no desempenho das vacas leiteiras não são facilmente quantificados pois existe grande variabilidade na resposta da produção de leite em relação à mastite (Lescourret \& Coulon, 1994). Este fato é devido a diferenças presentes nas populações estudadas, aos indicadores da mastite, e ao método estatístico utilizado (Hornet et al., 1999). Diferentes métodos têm sido utilizados para o estudo dos efeitos da mastite sobre a produção. Um deles é o estudo da alteração da produção em 305 dias em lactação associada ao aumento da média da CCS (ou de sua função log) durante a lactação (Raubertas \& Shook, 1982; Hornet et al., 1999).

Células somáticas são células da vaca presentes no leite. Normalmente são células de defesa (leucócitos) do organismo que migram do sangue para o interior da glândula mamária com o objetivo de combater agentes agressores, mas também podem ser células secretoras descamadas. Esta migração de leucócitos é resultado da ocorrência da mastite (Machado et al., 1999).

$O$ objetivo deste trabalho foi quantificar o efeito do nível de células somáticas, transformado para escore linear, sobre a produção de leite e de gordura em 305 dias de lactação, produção de leite no pico, e duração da lactação de bovinos da raça holandesa.

\section{MATERIAL E MÉTODOS}

Informações referentes a 147 lactações encerradas de bovinos da raça holandesa, de um rebanho confinado do Estado de São Paulo, foram levantadas no banco de dados do Laboratório de Fisiologia da Lactação da ESALQ - USP em Piracicaba, SP. O rebanho possui em média 398 vacas em lactação, da raça holandesa preto e branco. A média anual de produção por vaca é de $27,8 \mathrm{~kg} \mathrm{dia}^{-1}$. Os animais são manejados em sistema de confinamento livre, e são ordenhados 3 vezes ao dia em uma única sala de ordenha do tipo espinha de peixe 12x12. As taxas de mastite subclínica (EL > 4,5), mastite clínica, de novas infecções e taxa de mastite crônica são respectivamente 24,$9 ; 1,6 ; 13,5$ e $63,2 \%$.

Predominam mastites causadas por patógenos menores (Corynebacterium bovis e estafilococos coagulase negativa).

Das lactações, 83 eram de animais primíparos e 64 de animais multíparos. Optou-se por estudar separadamente o efeito da CCS sobre os parâmetros produtivos de animais primíparos e multíparos. As informações levantadas foram a produção de leite e gordura em 305 dias de lactação, a produção no pico de produção, a duração da lactação e as médias de escore linear na lactação e no seu início. O escore linear havia sido previamente calculado, apartir da CCS, utilizandose a função $E L=\left[\log _{2}(C C S / 100.000)\right]+3$, proposta por Dabdoub \& Shook (1984).

As análises estatísticas foram realizadas no pacote estatístico SAS (SAS Institute, 1990), utilizandose o módulo "SAS assist". Os modelos estatísticos utilizados foram:

$$
Y_{i}=a+b E_{i}+e_{i}
$$

onde: $Y_{i}=$ observação referente a produção de leite ou gordura, em kg, aos 305dias de lactação ou a duração da lactação, em dias, referente ao escore linear i; $a=$ intercepto; $b=$ inclinação da reta; $E_{i}=$ efeito do escore linear médio da lactação $i$, sendo $i=1, \ldots, 10 ; e_{i}=$ erro aleatório associado a observação $Y_{i}$.

$$
Y_{i}=a+b l_{i}+e_{i} ;
$$

onde: $Y_{i}=$ observação referente a produção de leite, em $\mathrm{kg}$, no pico de produção referente ao escore linear médio no início da lactação i; $a$ = intercepto; $b=$ inclinação da reta; $I_{i}=$ efeito do escore linear médio do início dalactação $i$, sendo $i=1, \ldots, 10 ; e_{i}=$ erro aleatório associado a observação $Y_{i}$.

\section{RESULTADOS E DISCUSSÃO}

\section{Análise do rebanho}

O rebanho apresenta média de produção superior às médias encontrados em rebanhos holandeses por Richter et al. (1995) e Pimpão et al. (1997) no Paraná, respectivamente, 6300 e 6400 kg, e por Reis \& Silva (1987) e Barbosa (1990) em rebanhos de Minas Gerais (4500 kg) e Pernambuco (4600 kg) (TABELA 1). A produção média de gordura também foi

\begin{tabular}{|c|c|c|c|c|}
\hline & \multicolumn{2}{|c|}{ Primíparas } & \multicolumn{2}{|c|}{ Multiparas } \\
\hline & Média & $\mathrm{CV}$ & Média & CV \\
\hline & $\mathrm{kg}$ & $\%$ & $\mathrm{~kg}$ & $\%$ \\
\hline PL305* & 8478 & 11,74 & 10051 & 12,44 \\
\hline PG305** & 308,2 & 16,95 & 387,2 & 16,50 \\
\hline$D L^{* * *}$ & 378,5 & 17,70 & 399,4 & 16,29 \\
\hline PICO. & 33,4 & 14,17 & 44,4 & 11,87 \\
\hline DP.. & 61,4 & 15,52 & 55,3 & 15,73 \\
\hline EL $\cdots$ & 2,15 & 60,28 & 3,4 & 40,81 \\
\hline MEDIN|x & 2,39 & 67,2 & 3,2 & 66,13 \\
\hline $\mathrm{N}^{\mathrm{xx}}$ & \multicolumn{2}{|c|}{83} & \multicolumn{2}{|c|}{64} \\
\hline
\end{tabular}
superior à dos trabalhos citados acima.

*produção de leite em 305 dias de lactação, em kg, **produção de gordura em 305 dias de lactação, em kg, ${ }^{* * *}$ duração da lactação, em dias, 'produção de leite no pico de lactação, em kg, '“data de ocorrência do pico, em dias de lactação, - 'escore linear médio da lactação, 'escore linear médio no inicio da lactação, ${ }^{\times}$número de observações. 
O alto nível de produção é provavelmente devido às condições nutricionais e sanitárias do rebanho. Colaborando com esta hipótese, o escore linear médio da lactação encontrado é de apenas 2,15 para primíparas e 3,4 para multíparas evidenciando uma boa condição de sanidade da glândula mamária.

Os coeficientes de variação foram inferiores aos CV das respostas animais em geral (20 a 30\%) (Sampaio, 1998). Isso mostra o alto controle da atividade produtiva existente na propriedade.

O escore linear médio da lactação inteira e de seu início se mostraram, no entanto, altamente instáveis (CV 40 a 67\%). Esta instabilidade decorre de que com o bom manejo sanitário do rebanho poucos animais são afetados pela mastite de modo a apresentar média da lactação inteira de escore linear alto, predominando assim, baixos valores de EL.

\section{Primíparas}

A análise de regressão não mostrou efeito $(P>0,10)$ do escore linear médio da lactação (EL) sobre a produção de leite e gordura em 305 dias em lactação, nem sobre a duração da lactação, e nem efeito do escore linear médio do inicio da lactação sobre a produção de leite no pico e a data do mesmo. A ausência de efeito do EL sobre os parâmetros estudados contraria a literatura (Raubertas \& Shook, 1982; Miller et al., 1993; Graafa \& Dwingerb, 1996), mas pode ser explicada pela quase inexistência de animais primíparos com EL médio da lactação acima de 4,5 (Figuras 1, 2, 3, e 4). Praticamente todos os animais primíparos do rebanho estudado apresentam EL médio da lactação abaixo de 4,5 (Figura 1). Desse modo, a análise de regressão não indicou efeito do EL sobre a produção de leite e gordura aos 305 dias de lactação (Figuras 2 e 3), nem sobre a duração da lactação (Figura 4).

Médias de EL da lactação inteira abaixo de 3,5 não afetam as características produtivas de primíparas nas condições estudadas (Figuras 2, 3, e 4).

A distribuição dos dados de média de escore linear no início da lactação (MEDINI) também se comportou como a distribuição dos dados de escore linear médio da lactação inteira ( $E L)$ com pequeno número de animais com valores mais altos. Esta baixa freqüência de animais com média de escore linear no início da lactação (MEDINI) acima de 4,5 levou a análise de regressão a não detectar efeito da mesma sobre a produção de leite no pico da lactação (PICO) nem sobre a data de ocorrência do mesmo (DP).

\section{Multíparas}

Inicialmente realizou-se a análise de variância estudando-se a interação entre o $\mathrm{EL}$ e número de lactações, no entanto como nenhum parâmetro analisado apresentou efeito significativo da interação estudou-se o efeito do EL independentemente do número de lactações. O resumo da análise de regressão do efeito da média do escore linear sobre os parâmetros estudados se encontra na TABELA 2.

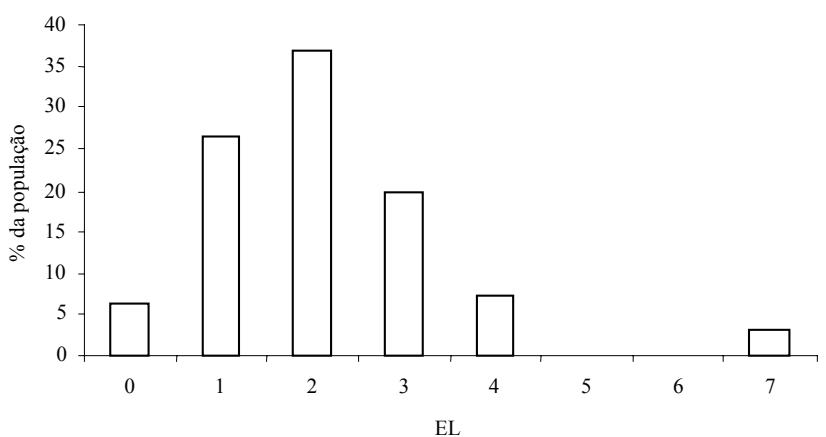

Figura 1 - Distribuição dos dados de escore linear (EL) das primíparas.

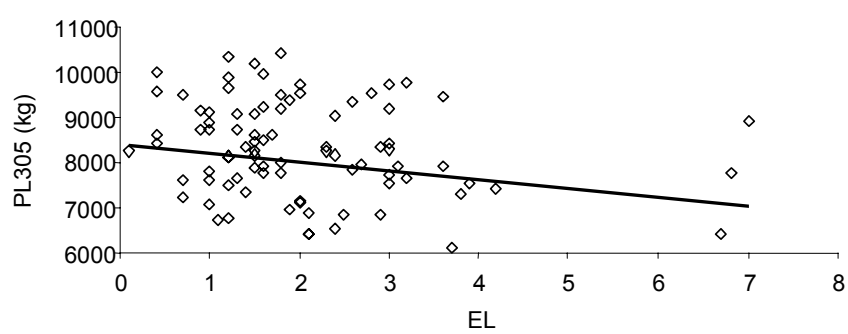

Figura 2 - Produção de leite em 305 dias em lactação (PL305) em função do escore linear médio da lactação (EL) dos animais primíparos.

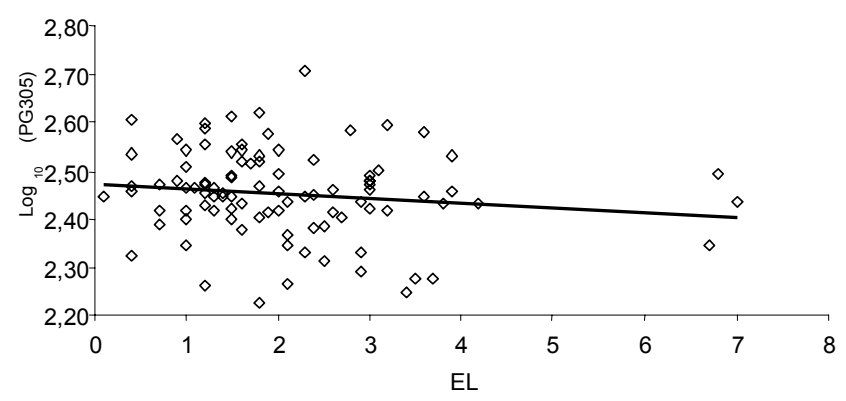

Figura 3 - Efeito do escore linear médio da lactação (EL) sobre a produção de gordura em 305 dias de lactação (PG305) transformada para $\log _{10}$ dos animais primíparos.

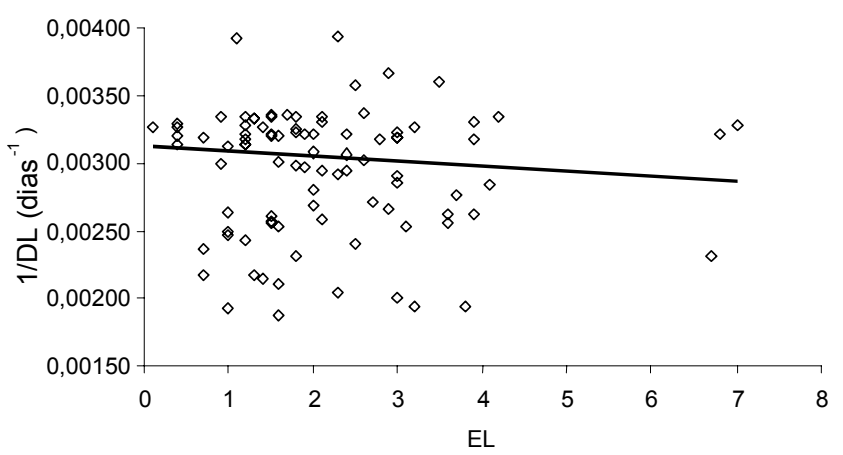

Figura 4 - Efeito do escore linear médio da lactação (EL) sobre o inverso da duração da lactação (1/DL) dos animais primíparos. 
TABELA 2 - Resumo da análise de regressão do efeito do escore linear médio da lactação sobre a produção de leite e gordura em 305 dias em lactação, sobre a duração da lactação, e efeito escore linear médio do início da lactação sobre a produção de leite no pico e a data do mesmo em multíparos.

\begin{tabular}{|c|c|c|c|c|c|c|c|}
\hline & $\begin{array}{c}G L^{\mathrm{u}} \\
\text { modelo }\end{array}$ & $\begin{array}{c}G L^{100} \\
\text { resíduo }\end{array}$ & $\begin{array}{l}\mathrm{GL}^{\mathrm{and}} \\
\text { Total }\end{array}$ & $\begin{array}{c}\text { nis }^{\square \bullet \square} \\
\%\end{array}$ & $\mathrm{R}^{2} \mathrm{aj}{ }^{\square \bullet \bullet}$ & $\begin{array}{l}\mathrm{CV} \\
\%\end{array}$ & Equação \\
\hline PL305* & 1 & 62 & 63 & 1 & 0,1076 & 11,75 & PL305 = 11119 - 315,0 (ELㅁ) \\
\hline PG305** & 1 & 62 & 63 & 5 & 0,0614 & 15,99 & PG305 = 430,4 - 12,75 (EL \\
\hline$D L^{* * *}$ & 1 & 62 & 63 & ns & - & 2,47 & - \\
\hline PICO• & 1 & 62 & 63 & 1 & 0,0891 & 11,33 & $\mathrm{PICO}=47,01-0,815$ (MEDINI ) \\
\hline DP*• & 1 & 62 & 63 & ns & - & - & - \\
\hline
\end{tabular}

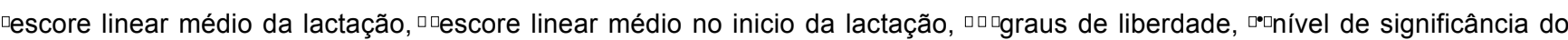
modelo, ${ }^{* *}$ Coeficiente de determinação, *produção de leite em 305 dias de lactação, em kg, ** produção de gordura em 305 dias de lactação, em kg, ${ }^{* *}$ duração da lactação, em dias, transformado por indicação da análise de máxima verosimilhança para log ${ }_{10}$, -produção de leite no pico de lactação, em kg, "•data do pico de lactação, em dias, transformado por indicação da análise de máxima verosimilhança para 1/DP.

A produção de leite em 305 dias de lactação mostrou-se estar associada com o escore linear médio de maneira linear (Figura 5). Este fato é respaldado pela literatura (Raubertas \& Shook, 1982; Dabdoub \& Shook, 1984; Fetrow et al., 1988; Sender et al., 1996). A diminuição da produção de leite é devido a destruição do tecido secretor pela ação dos microrganismos na glândula mamária e pela migração de leucócitos para o interior da glândula (Philpot \& Nickerson, 1991).

A comparação entre as perdas devido ao aumento do escore linear é dificultada devido à variação entre as metodologias utilizadas, no entanto Dabdoub \& Shook (1984), Reneau (1986) e Fetrow et al. (1988) utilizando o escore linear médio da lactação e a produção acumulada encontraram as seguintes perdas: 146 a 213 $\mathrm{kg}, 181 \mathrm{~kg}$ e $190 \mathrm{~kg}$ de leite. Aqueles autores não apresentam a produção média dos animais estudados, mas devido ao alto nível de produção dos animais deste trabalho é possível supor que a maior perda associada ao aumento do EL médio da lactação encontrada neste trabalho $(315 \mathrm{~kg})$ seja devido ao maior potencial de produção dos animais.

O coeficiente de determinação encontrado mostra que de 10,8\% da variação da produção de leite pode ser explicado pelo escore linear, outros fatores não incluídos no modelo foram responsáveis pelo resto da variação.

$A$ análise de regressão indicou efeito do $E L$ sobre a produção de gordura (TABELA 2 e Figura 6). Outros autores apresentaram redução da produção de gordura relacionada com o aumento da CCS (Kennedy et al., 1982; Gadini et al., 1997; Norman et al., 1999). A redução da produção deste componente é devida aos mesmos fatores da redução de produção do leite. Assim como na produção de leite, a produção de gordura é afetada por outros fatores não modelados neste trabalho. Desse modo o coeficiente de determinação encontrado $(6,1 \%)$ é bastante baixo. A variabilidade da produção de leite encontrada foi $26,5 \%$ menor que a variabilidade da produção de gordura.

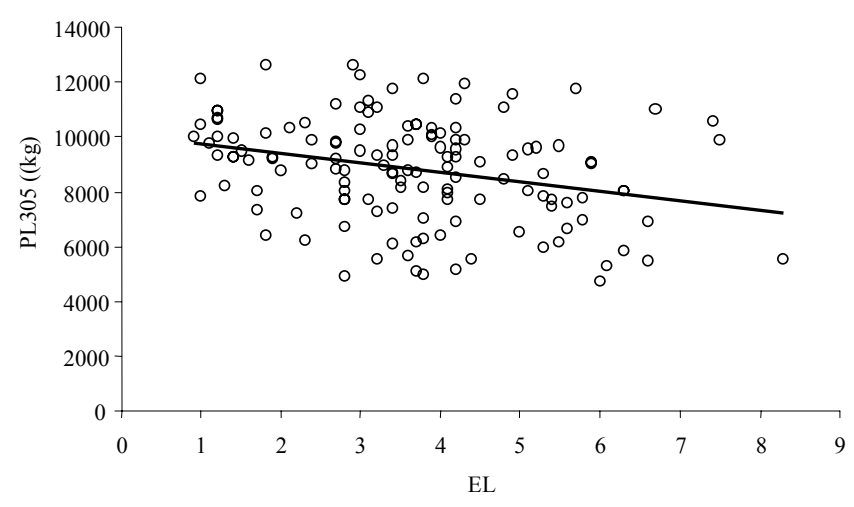

Figura 5 - Produção de leite em 305 dias (PL305) em lactação em função do escore linear médio da lactação (EL) dos animais multíparos.

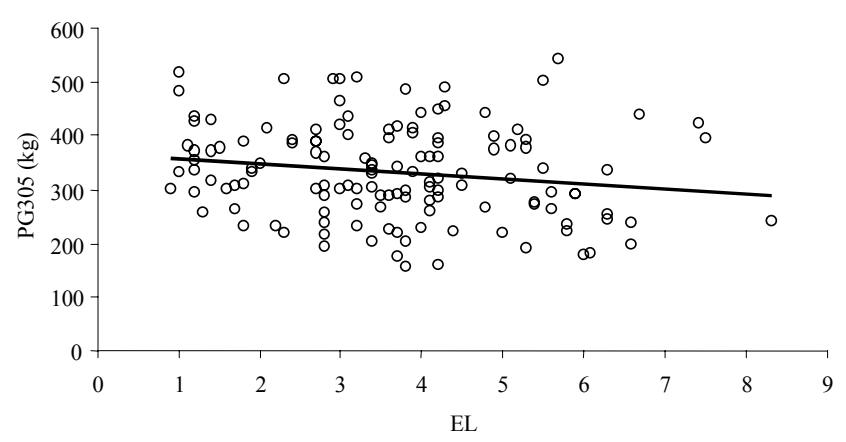

Figura 6 - Produção de gordura em 305 dias em lactação em função do escore linear médio da lactação $(E L)$ dos animais multíparos.

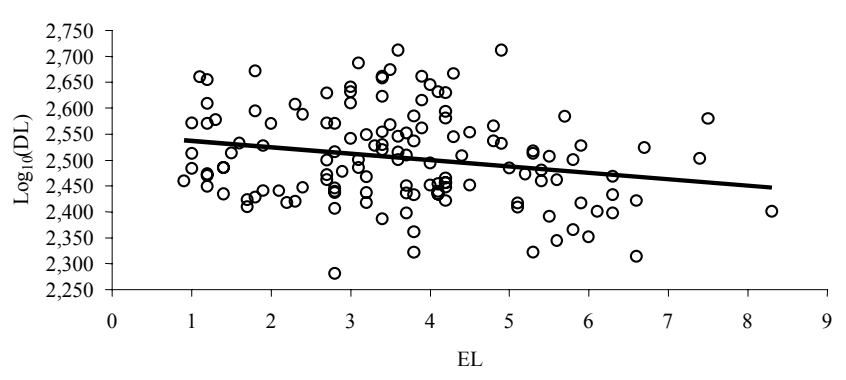

Figura 7 - Duração da em lactação (transformado para $\log _{10}$ ) em função do escore linear médio da lactação (EL) dos animais multíparos. 


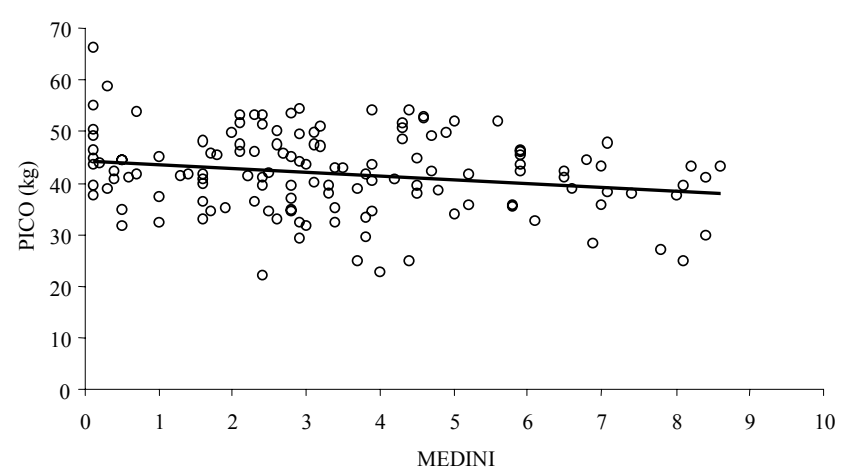

Figura 8 - Produção de leite no pico em função do escore linear médio do início da lactação dos animais multíparos.

Os dados de duração da lactação (DL) foram transformados para a função $\log _{10}$ para poderem ser modelados. A função de transformação foi indicada por análise de máxima verossimilhança do pacote estatístico SAS e diminuiu a variabilidade dos dados em $15 \%$, melhorando sua distribuição em torno da reta.

Apesar de aparente diminuição da duração da lactação relacionada ao aumento do escore linear médio da lactação esta não foi significativa $(P>0,10)$ (TABELA 2 e Figura 7). Provavelmente a existência de 2 animais com EL relativamente alto (cerca de 5 e 6 ) e lactações longas levaram a não significancia do efeito.

Machado et al. (1993) observaram redução da duração da lactação associada a ocorrência da mastite. A redução da duração da lactação pode ser explicada pela diminuição da produção de leite. Segundo Grôhn (1998), animais com mastite têm maior chance de serem descartados. Além disso animais no fim da lactação que apresentam alta CCS podem ser secos para serem tratados, levando assim a diminuição da duração da lactação.

A produção de leite no pico foi afetada pelo escore linear no início da lactação (MEDINI) levando a diminuição da mesma (TABELA 2 e Figura 8). O coeficiente de determinação desse parâmetro também foi muito baixo uma vez que apenas $8,9 \%$ da variação da produção no pico pode ser explicado pela média do escore linear no início da lactação.

A data de ocorrência do pico de produção não foi afetada pela média do escore linear no início da lactação (TABELA 2).

\section{CONCLUSÃO}

Os valores referentes às contagens de células somáticas, quando convertidas para escore linear, apresentaram um efeito negativo sobre a produção de leite e gordura em 305 dias, embora a CCS tenha sido responsável por uma pequena parcela da variabilidade encontrada sobre a produção de leite e gordura. $\mathrm{O}$ aumento de apenas uma unidade de EL correspondeu a uma redução de $315 \mathrm{~kg}$ de leite e $12,75 \mathrm{~kg}$ de gordura por animal em 305 dias de lactação.

\section{REFERÊNCIAS BIBLIOGRÁFICAS}

BARBOSA, S.B.P. Estudo de características produtivas em rebanhos holandeses na bacia leiteira do estado de Pernambuco. Viçosa, 1990. 121p. Tese (Doutorado) Universidade Federal de Viçosa.

BLOOD, D.C.; RADOTITIS, O.M. Veterinary medicine: a textbook of the diseases of cattle, sheep, pigs, goats and horses. Londres: Bailliere Tindall, 1989. 1502p.

DABDOUB, S.A.M.; SHOOK, G.E. Phenotypic relations among milk yeld, somatic cell count, and clinical mastitis. Journal of Dairy Science, v.67, p.163-164, 1984. Suplemento 1.

FETROW, J.; ANDERSON, K.; SEXTON, S.; BUTCHER, K. Herd composite somatic cell counts: averege linear score and weighted averege somatic cell score and milk production. Journal of Dairy Science, v.71, p.257-260, 1988.

GADINI, C.H.; KEOWN, J.F.; VLECK, L.D.V. Parâmetros genéticos das produções de leite, gordura e proteína, e do escore de células somáticas em 305 dias de lactação. In: REUNIÃO ANUAL DA SOCIEDADE BRASILEIRA DE ZOOTECNIA, 34., Juiz de Fora, 1997. Anais. Juiz de Fora: SBZ, 1997. v.3, p.41-43.

GIRAUDO, J.A.; CALZOLARI, A.; RAMPONE, H.; RAMPONE, A.; GIRAUDO, A.T.; BOGNI, C.; LARRIESTRA, A.; NAGEL, R. Field trials of vaccine against bovine mastitis. 1. Evaluation in heifers. Journal of Dairy Science, v.80, p.845-853, 1997.

GRAAFA, T.; DWINGERB, R.H. Estimation of milk production losses due to sub-clinical mastitis in dairy cattle in Costa Rica. Preventive Veterinary Medicine, v.26, p.215-222, 1996. / Resumo em CAB Abstracts on CD-ROM, 1996-1998/07.

GRÔHN, Y.T. Studies examine possibility of milk yield, disease link. Feedstuffs, v.70, p.13-28, 1998.

HORNET, P.; BEAUDEAU, F.; SEEGERS, H.; FOURICHON, C. Reduction in milk yield associated with somatic cell counts up to 600000 cells $/ \mathrm{ml}$ in french Holsteins cows without clinical mastitis. Livestock Production Science, v.61, p.33-42, 1999.

JAIN, N.C. Common mammary pathogens and factors in infection and mastitis. Journal of Dairy Science, v.62, p.128-134, 1979.

KENNEDY, B.W.; SETHAR, M.S.; MOXLEY, J.E.; DOWNEY, B.R. Heritability of somatic cell counts and its relationship with milk yield and composition in Holsteins. Journal of Dairy Science, v.65, p.843-847, 1982.

LANGENEGGER, J.; COELHO, N.M.; LANGENEGGER, C.H.; CASTRO, R.P. de. Estudo da incidência da mastite bovina na bacia leiteira do Rio de Janeiro. Pesquisa Agropecuária Brasileira, v.5, p.437-440, 1970.

LARANJA, L.F.; MACHADO, P.F. Ocorrência de mastite bovina em fazendas produtoras de leite B no estado de São Paulo. Scientia Agricola, v.51, p.578-585, 1994.

LESCOURRET, F.; COULON, J.B. Modelling de impact of mastitis on milk production by dairy cows. Journal of Dairy Science, v.77, p.2289-2301, 1994.

MACHADO, P.F.; BARANCELLI, G.; PEREIRA, A.R. CCS: Leite com mais qualidade e melhor rendimento industrial. Indústria de Laticínios, v.2, p.65-68, 1998.

MACHADO, P.F.; PEREIRA, A.R.; SARRÍES, G.A. Efeitos da contagem de células somáticas na qualidade do leite e a atual situação de rebanhos brasileiros. Revista do Instituto de Laticínios "Cândido Tostes", v.54, p.10-16, 1999.

MACHADO, S.G.; CARDOSO, V.L; SILVA, A.M.S.; FREITAS, M.A.R. Influência da ocorrência da mastite na produção de leite e duração da lactação. In: REUNIÃO ANUAL DA SOCIEDADE BRASILEIRA DE ZOOTECNIA, 30., Rio de Janeiro, 1993. Anais. Rio de Janeiro: SBZ, 1993. p.587. 
MILLER, R.H.; PAAPE, M.J.; FULTON, L.A.; SCHUTZ, M.M. The relationship of milk somatic cell count to milk yields for Holteins heifers after first calving. Journal of Dairy Science, v.76, p.728-733, 1993.

NADER FILHO, A.; SCHOCKEN-ITURRINO, R.P.; ROSSI JUNIOR, O.D.; CEMBRANELLI, E.M. Prevalência e etiologia da mastite bovina na região de Ribeirão Preto. Pesquisa Veterinária Brasileira, v.5, p.53-56, 1985.

NORMAN, H.D.; VANRADEN, P.M.; WRIGHT, J.R.; SMITH, L.A. Mathematical representations of correlations among yield traits and somatic cell score on test day. Journal of Dairy Science, v.82, p.2205-2211, 1999.

PHILPOT, W.N. Control of mastitis by hygiene and therapy. Journal of Dairy Science, v.62, p.168-176, 1979.

PHILPOT, W.N.; NICKERSON, S.C. Mastitis: counter attack. Naperville: Babson Bros., 1991. 150p.

PIMPÃO, C.T.; RIBAS, N.P.; MONARDES, H.; ALMEIDA, R. de. Estudo dos efeitos do meio ambiente sobre as características produtivas de vacas da raça holandesa da região de Arapoti, Estado do Paraná. Revista Brasileira de Zootecnia, v.26, p.494-500, 1997.

POLITITIS, I.; HIDIROGLOU, M.; BATRA, T.R.; GILMORE, J.A.; GOREWIT, R.C.; SCHERF, H. Effects of vitamin E on immune function of dairy cows American Journal of Veterinary Research, v.56, p.179-184, 1995.

RAUBERTAS, R.F.; SHOOK, G.E. Relationship between lactation measures of somatic cell concentration and milk yield. Journal of Dairy Science, v.65, p.419-425, 1982.
REIS, R.B.; SILVA, H.M. Influência de alguns fatores do meio sobre as principais características produtivas em rebanhos holandeses. I - Produção de leite, produção de gordura, porcentagem de gordura. Arquivo Brasileiro de Medicina Veterinária e Zootecnia, v.39, p.273-290, 1987.

RENEAU, J.K. Effetive use of dairy herd improvement somatic cell count in mastitis control. Journal of Dairy Science, v.69, p.1708-1720, 1986.

RICHTER, G.O.; RIBAS, N.P.; MONARDES, H.G.; ALMEIDA, R.; VEIGA, D.R. Estudo da produção de leite, produção de gordura e porcentagem de gordura em vacas da raça holandesa, região de Witmarsum, Palmeira, Paraná. Revista do Setor de Ciências Agrárias, v.14, p.141-149, 1995.

SAMPAIO, I.B.M. Estatística aplicada a experimentação animal. Belo Horizonte: Fundação de Ensino e Pesquisa em Medicina Veterinária e Zootecnia, 1998. 221p.

SAS Institute. SAS/STAT user's guide. Version 6. 4.ed. Cary: Statistical Analysis System Institute, 1990. 1022p.

SENDER, G.; LUKASZEWICH, M.; ROSOCHOWICZ, L.; DORYNEK, Z. Economic value of somatic cell count with special emphasis to polish conditions. Stocarstvo, v.50, p.361-362, 1996./Resumo em CAB Abstracts on CD-ROM, 1996-1998/07.

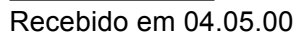

